\title{
Assumed voices of Samoa
}

\author{
Tautalamaleavailumaotamalii (Tala) Anastasia Faletolu
}

Tautalamaleavailumaotamalii (Tala) Anastasia Faletolu (nee Aiono) is Samoan born and raised in Dunedin. Tala comes from the villages of Matautu Lefaga and Fasito'o-Uta with linkages to Sa'anapu and Malie. Educated at Otago University with a Master of Social Welfare, Tala now works as an Advisor for Learning and Development for the Department of Child, Youth and Family. Tala's strong passion area is in frontline practice for Child Protection where she applauds the concept of understanding and practising cultural diversity within social work practice. Tala's future goal is to continue researching and writing practice tools to provide better understanding around Pacific issues and fuel 'best practice' around working with Pacific families. Tala is supported by her husband Ueli and their four children (Ma'ole, Toloumu, Fiatamali'i and Ina'ilau).

I know who I am however (at times) it can be frustrating and difficult when explaining to others and I don't mind that (so much) ... what I don't like is when people assume that they know who I am and proceed to relate to me with their assured understanding and ignorance (Anonymous).

In 2007 I started studying towards a Master in Social Welfare, a two-year qualification with a strong focus on practice based knowledge. Struggling for a topic to research, my head was telling me to find something that would suit the academic minds and passions, but my heart was telling me to write for my people. With a strong passion for front-line practice, and using my experiences of what I found, I saw that there was a gap in practice policies specifically for cultures from the Pacific. Working as a social worker for Child, Youth and Family, it was common practice for my colleagues to go in 'blindly', and/or rely on their social work instincts to help them through cultural misunderstandings. I also saw a common practice of social workers practising from Maori practice policies. When questioning my colleague around this practice, they would often say that:

- There are no Pacific policies.

- They don't know how to work the Pacific practice policy at hand.

- Both cultures are similar so therefore it won't make a difference what policy is used.

In this article I will be giving you an overview of the research that I undertook titled 'The Assumed Voices of Samoa', and the founding conclusions that I made in answer to the research question of 'What are some appropriate ways of working social work with Samoan people from a Samoan client's perspective?' Accounts from participants will be shared to highlight the importance of understanding cultures to avoid miscommunication, disempowerment and disrespect. Finally the 'So' otaga Model' will be explained to show required skills, knowledge, resources and supports when working with Samoan families.

Let me start this article by explaining to you, the reader, why I chose to work within my own culture and not include cultures from other nations of the Pacific. First and foremost, I believe that I need to have the 'right' to enter into a culture and I have the right to enter into the Samoan culture because I am a Samoan, born into the Samoan culture, serving the Samoan culture through my church, my family, my children, my language and my geneal- 
ogy. My hesitancy to include cultures from other parts of the Pacific rested on the belief that I do not have the 'right' to enter into other cultures. I interpreted 'right' to be based on birthright, servitudinal right and heritage.

Why did I want to look at a topic that (according to my academic seniors) could be borderline 'repetitive' with other similar topics researched in the past? A felt need from a personal experience as a young child facing intrusive and racially discriminatory practices of health support workers sparked this topic. As long as I see that there are continued 'gaps' in cross-cultural practice, then research such as this may possibly continue.

\section{There is an 'I' in PI - 'l' for individuality}

One particular area of uncertainty is around defining cultural groups. How we define ourselves and how others define us can always cause conflict. One problematic area which can cause barriers is around understanding definitions of 'Pacific peoples'. Pacific people themselves will have a different definition to that of non-Pacific people. This leads to another problematic barrier, which is how to 'work' with people from the Pacific when definitions of what a Pacific person/community is varied by different parties and is not clarified for all. Growing up as a Samoan and being labelled as a 'Pacific person', I found that the understandings of the various cultures from the Pacific were 'blended' and 'confused'.

Within this paradigm Maori and Pacific Islands peoples are sometimes grouped together as Polynesian, especially where they appear to be in similar socio-economic circumstances. This ignores the differences, not only between Maori and Pacific Islands people, but also cultural, historical and legal differences that are thus overlooked (Earle, 1995, p. 17).

The dominant existing paradigm is to treat Pacific Island peoples as a minority ethnic group. The term 'minority' places Pacific Island peoples in a subordinate position to the 'majority', generally seen as Pakeha. It assumes that social norms are set by the majority and that minorities have the choice of joining the majority (assimilation), or partially retaining their identity, so long as it doesn't conflict with majority requirements (integration) (Earle, 1995, p. 16).

The identity of Samoans living in New Zealand has been grouped under the category of 'Pacific Islanders'. A space to parade individual identity within the New Zealand culture has been difficult. Policies and strategies developed to support individual Pacific Island nations are minimal. 'As people of the 'Pacific' we know full well our differences and expect/wish to be understood and celebrated for our uniqueness' (Earle, 1995).

Firstly, groups do not become Pacific Islanders until they arrive in New Zealand. It is a term that has been imposed by Palagi and, in strictly logical terms, it does not make a lot of sense. New Zealanders, whether Palagi, Maori or Samoan, are all Pacific Islanders (PulotuEndermann \& Spoonley, 1992, p. 82).

But the indigenous people of the Pacific know who they are - they are people of each particular Pacific island nation. The potential for confusion arises when attempts are made to classify them under one all encompassing name (Pilato, Su' a \& Crichton-Hill, 1998, p. 25).

Could this be the reason why there are very few social work practice policies and strategies specifically for individual Pacific island nations? 
Leading on from the above, it is fair to say that some of the difficulty of having a 'one size fits all' approach to Pacific policies and strategies is that they cannot directly pin-point individual cultural differences, and therefore cultural understanding and identities are not acknowledged and Pacific people will not necessarily feel 'connected' to a particular forced definition. Dr Southwick believes that a Pacific person will gain a sense of belonging only when the mainstream culture stops its negative stereotyping and generalisation of Pacific peoples. Only when this negativity stops will space be provided for Pacific peoples to feel a sense of belonging to New Zealand, hence accomplishing identity (Southwick, 2001, p. 21).

\section{Research with a Samoan spark}

Coming from a qualitative approach, my research process had to include elements of the Samoan culture so that the participants were able to feel 'connected' and 'included' in the process. In Table one Mulitalo-Lauta (2000) and Autagavaia (2001) describe factors that are important and vital to the survival of the Samoan culture through language, behaviour and protocols.

\section{Table one.}

Mulitalo-Lauta (2000)

Courtesy \& diplomacy

Respect for elders \& parents

A Samoan way of walking, talking, sitting and standing

The use of the Samoan language

Understanding the Samoan protocols

Sense of humility

A Samoan way of thinking

The social structures of Aiga (family and chiefs)

Samoan identity and Samoan ethnicity
Autagavaia (2001)

Aiga o le Fa'asinomaga -Family and identity

Va fealoaloa'i - Sacred space

Ava and Fa'aaloalo - Respect

Tautua - Stewardship

Fa'autauta - Knowledge and wisdom

Gagana - Language

Multi-methodology enables a researcher to gain an in-depth understanding of their research topic. Denzin \& Lincoln (2000) argue that combining multiple methodological practices and perspectives and observers as strategies gives richness, depth, rigor, complexity and breadth to any research inquiry (Denzin \& Lincoln, 2000, p. 13, citing Flick, 1998).

Research needs to be culturally inclusive ... Research is an avenue where indigenous voices have been heard but through constructs that are 'etic' (Baba, 2004).

Within the arena of fa' asamoa and its concept as described by Mulitalo-Lauta (2000), research methodologies constructed including these cultural aspects will protect the researcher and participants. Mutu (2004) supports the view that when researching Maori or Pacific people it is important to, ' ... adhere to those practices already condoned and practised within those communities' (Baba 2004, p. 95).

Mafile' o (2005) advocates for an ethnic-specific research base as opposed to a 'pan-Pacific base'. She believes that by having an ethnic-specific base, a culture is able to hold on to its 
uniqueness, celebrating and standing from the base of its own particular culture, customs and traditions. She believes that pan-Pacific base research can lose the uniqueness, customs and traditions of individual cultures as they could become diluted amongst other cultures. A one size fits all creates competitions amongst all cultures involved as each culture tries to uphold and keep their individual cultures alive.

\section{The participants' stories}

I was fortunate to locate six participants willing to share with me their stories and personal encounters with Palagi social work practitioners as a Samoan person. Each participant was selected based on:

- Working involvement with their social work practitioner was within the Dunedin area.

- Participants' involvements with their social work practitioner is no longer current.

- Participants have a strong connection to the Samoan culture through community, family, language, etc.

- Participants hold a good knowledge of the fa' asamoa culture.

Looking at the works of Autagavaia (Concepts of Fa'asamoa, 2001), Mulitalo-Lauta (The Lalaga Model, 2000) and Thomsen-Inder (Tanoa Model, 2003), I pulled out specific factors and qualities and aligned them to issues that came out of the participants' stories. From the above analysis process themes were highlighted and thus used to set out the data results.

\section{Themes}

1. Inclusiveness - The social worker's ability to ensure that the family felt included in the process.

I was a big, proud Samoan fresh kid and she was white ... Hmmm. She never included me, she just told me what to do and I had to do it. I remember one time she told she was concerned that I was obese ... like who made her a doctor. In her plan, which she kept telling me was OUR plan, she wrote down I was obese, therefore my self-esteem was low ... I was 6 foot 6 inches, solid, aged sixteen and I ate heaps, but I was fit and I didn't have a stomach. Nowadays people would kill to have my outlook (laughing) ... she took it upon herself to write me a diet ... (Laughing) I remember the first item on the list was four strawberries ... Well that plan didn't work because we couldn't afford it, but back then it was seen to be my family not trying ...

Court plans were done by (agency name). I was directed to do it and no allowance was given and no end or review date either. Plans to contact my baby were hard as the visits were so strict and little and I eventually had to nod my head and agree so that I wouldn't lose everything.

2. Cultural competence - the social worker's ability to promote the Samoan culture within the process, so the Samoan participants felt valued and their culture was recognised and honoured.

For goodness sake, do I really need to answer that? (Laughing.) Well she had none (referring to the social worker's level of cultural competence) and to make it worse she placed her values and beliefs on me and my family and my culture with no respect to who I am ...' 
Umm ... it was hard to think that she understood us because she had no understanding (Samoan culture). Yeah, it was hard to think that she did understand us because she kept saying things that were patronising.

3. Empowerment - the ability of the social worker to empower the family by ensuring the family's Samoan culture was maintained and included in the whole social work process and to ensure that the client/family was and felt valued at all times

One day she came to our house. Anyway my uncle is very strong in our culture and my aunt also lived in Samoa (she's Palagi), so had lots of Samoan decorations on the wall and lots of pictures of family members everywhere ... during my court appearance my social worker told the judge that I am a confused persona and that anyone would understand by visiting our house and seeing the different odd looking ornaments around the house.'

... when I was in her office she would talk about me, negatively, to her colleagues like I wasn't there.

4. Communication (language) - the ability of the social worker to recognise the differences in language communication and speech, and the social worker's ability to communicate appropriately and sensitively to the Samoan family

Patronising stereotyping ... and that we were a young couple...

Apart from everything that I have said, she spoke to me like I was dumb and I didn't understand the English language. I mean, I understood it (English), I just found it difficult to speak it back ...

5. Communication (non-verbal) - the ability of the social worker to recognise the different cultural non-verbal communication and the social worker's ability to produce appropriate non-verbal communication. Non-verbal communication refers to communication that is carried through body and facial stance and expressions.

... ummm, everything was hard for me and my family because she looked at us as dumb darkies from a poor family (rolling her eyes, taking long loud sighs, body position very closed). I felt useless with the way she looked at me.

6. Sensitivity - the ability of the social worker to be sensitive to the family's Samoan culture.

Yeah, one time she came to visit me and it was during her lunch hour. She sat there in front of me and ate her sandwich, not even offer me some. You know in our culture you either, hold out, offer half or all, wait or make sure you have another for the other person. She even ate in front of my uncle and aunt and then asked me to put her sandwich wrap in OUR rubbish bin ...

... she passed judgement on the fact that we're a young brown couple ... Didn't she? Without knowing ... yeah, yeah ... Like saying to us that when we got the cot she'd come up and check that we got the right blank - the absolute inability to acknowledge that we had family support.

She would always refer to the Maori culture, believing that we were the same. She insisted with my uncle that somewhere in Samoa we must have our version of a marae. My uncle tried 
to explain that we have a meeting house and she asked if we had carvings on our meeting houses like the Maori people. Well, my uncle had to explain that there were no walls and no wood carvings. She told us that we were wrong and that people from our types of countries worshipped wood carvings ...

During one conversation we had, we were in the car and she told me that I needed to pull my head out and do something with my life or else the only thing I would be good at is collecting rubbish ...

7. Power dynamics - Look at where the social worker placed the power when working with the Samoan family and the assumption of knowledge the social worker held about the Samoan culture.

No strength and positive focused, always blamed me for everything that went wrong and always instructed never suggested ...

Another time, I was with her in her office and I felt that everyone was looking at me and I heard her tell MY story to another colleague. Again, I was angry and I looked at her angrily and she kept saying that I was a very angry person and I needed counselling ... so I had counselling, I did what I was told ... I only had that first session, never went back for any more. Anyway I was asked as to why I had come to counselling ... well what was I supposed to say? I didn't know - I was told that I had to go, so I went. Well, I was recorded not engaging and showing lack of enthusiasm ... I wasn't going to tell them things about me. I just met this person. Good one!

8. Boundaries - the social worker's ability to implement culturally safe and appropriate boundaries, both in statements made by the social worker and within behaviours of the social worker towards the Samoan family.

... she wanted me to find an activity that would keep me busy on Friday nights, so she suggested a youth group. I said no, because I knew my uncle's church ran a youth group so it wouldn't look good for the minister's nephew to be going to another youth group ... I tried to explain this to her and she said 'rubbish, we all pray to the same God' ... so I went with my uncle's blessing, but when I got there I found it hard. Yeah, OK they cater to a different group of youth, so I was hearing a few more swear words than I would normally find in my youth group and another strange thing I found was that these (teenagers) came together for youth group, it wasn't like they were from the same church or that their parents knew each other ... so when I told this to my social worker, again, she thought I was being difficult and told me that I would be used to hearing swear words as she was sure that they would be found in my youth group.

9. Options - if they were given an option of a Samoan social worker would they choose to have one?

Yes, but are there any? They would also see me as an equal.

Yes, they would know what kind of lifestyle I come from and also our father would have felt more comfortable.

10. Suggestions - what suggestions did the participants give which they believe would help improve social work practice of Palagi social workers to Samoan families?

Being in this industry of social work, they should know who they are working with ... 
Of course there needs to be more training and as a social worker, it needs to come from the initial training you know within tertiary and training programme.

There is a need to implement and integrate a policy within the framework around Pacific knowledge and practice.

It is important to note that two groups were formed out of the participants' stories. Group $A$ is where participants felt mistreated and told of unfortunate and negative experiences. Group B is where two out of the six participants felt that they had positive experiences. However in saying that, both groups stated strongly that their social worker held no knowledge, skills, language ability to be classed as culturally competent and both groups stated strongly that training and practice workshops would have benefitted their social worker in understanding their culture.

The two participants from Group B felt included, felt that the social worker was sensitive, felt that the power dynamics were equally shared, that non-verbal communication was safe and appropriate and felt that boundaries were kept safe. In saying this, the two participants listed that their social worker displayed skills in good listening, open discussion, seeking consent, organising meetings to suit the family's time, creating plans together and seeking cultural supervision to support their practice. Though these skills supported the social worker, it does not give a good indication that the social worker held a good level of Samoan cultural knowledge, language and protocols in order to ensure that elements of cultural competence, cultural empowerment, cultural sensitivity, cultural boundaries etc were met. Therefore these two participants agreed with the other four participants that cultural competence was lacking and training is imperative to support best practice when working with Samoan clients/families and communities.

Listed below are key words from the participants' stories.

Table two.

Negative
Ignorance
Worthlessness
Mistrust
Disrespect
Single power ownership, mainly to
the social worker/organisation
No collaborative working style
Racism and racial discrimination
Isolation
Insensitivity
Tiresome
Judged/stereotyped
Not valued as a person
Exclusive

\section{Negative}

Ignorance

Mistrust

Disrespect

the social worker/organisation

No collaborative working style

Racism and racial discrimination

Isolation

Insensitivity

Tiresome

Judged/stereotyped

Exclusive

\section{Positive}

Inclusive of family and culture

Caring

Understanding

Non-judgemental

Patient

Calm approach

Good listening

Empathy

Willing to learn

Respect

Sensitive

Accommodating

Share power

On-going consultation 


\section{Recommendations}

\section{Who are responsible - we are all responsible!}

We are all responsible in some form for ensuring that there are adequate and appropriate and safe training programmes to ensure that not only the Palagi but also non-Samoan social work practitioners have the knowledge and skills to produce best social work practice when working with Samoan clients/families and communities.

The Pentagon of Responsibility (Figure one) provides an illustrated view of where 'responsibility lies' and you will see (as in the Samoan way) it is the duty of all parties involved.

Figure one. The Pentagon of Responsibility.

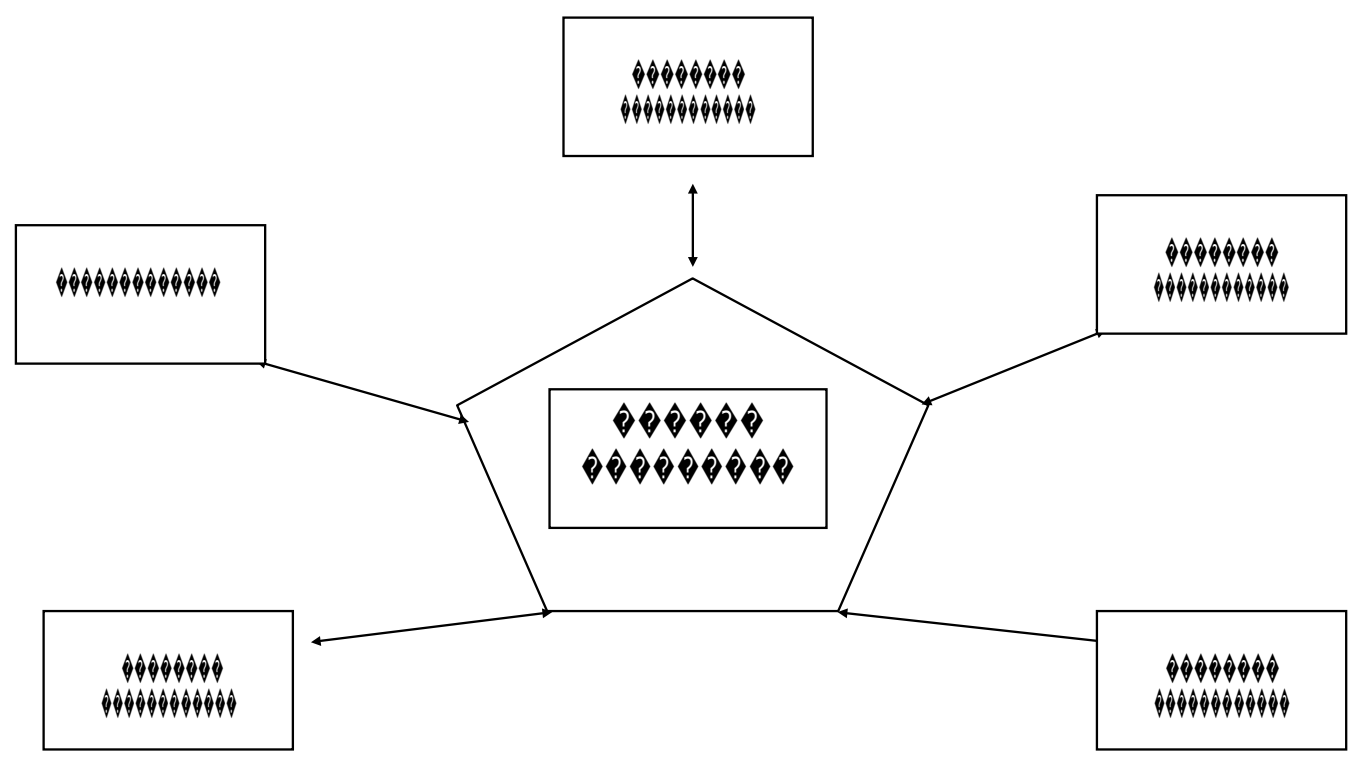

The Samoan community holds some responsibility to voice their views and concerns either directly to the government or to agencies

Learning institutions, such as universities, polytechnics and any other training providers need to be ensuring that the skills and knowledge they teach should include elements of Pacific cultures, with a specific mention of individual cultures. Training provided needs to reflect the cultural groups that are entering into the social service sectors, so that social work practitioners are exiting training with a 'well rounded' qualification that ensures that they have the cultural knowledge and skills to provide best practice to different cultural groups. There can be no excuse that curriculum and budget restraints make it difficult to include such training, because there is a danger that when 'qualified' social work practitioners enter into the field they will be faced with working with Samoan families and with no knowledge to work from. Learning institutions needs to ensure that their social work curriculum programme should cover such cultural issues, keeping in line with Aotearoa New Zealand Association of Social Workers (ANZASW) Practice Standards and other social work codes of ethics/conduct. 
Social work students must also be proactive in asking for more information and curriculum subjects that support their practice once they are out in the field.

Social workers are on the front line of social work, and can relay direct concerns to their management regarding the cultural training they need. Social workers can see the gaps around knowledge and skills and request appropriate professional development around this area. The social worker should also look for and request outside supervision.

It is the responsibility of the government to fund appropriate services for all its citizens. It is the government's responsibility to require Palagi social workers to have good knowledge of Samoan culture so that social workers can provide a good social work service. Governments can do this by creating policies, review groups and strategies to ensure that learning is gained, maintained and reviewed.

Organisations are responsible for ensuring their workers practise in safe and appropriate ways. They can arrange and support workplace development through local cultural workshops, or hold workshops within their agency and contract suitable trainers. The cultural competency of their social workers needs to be reviewed regularly so that social worker knowledge on cultural matters is in line with the need.

\section{Specifically-Pacific rather than Pan-Pacific}

The state-structured classification of 'Pacific' placed on all Pacific people (Meleisea \& Schoeffel, 1998, p. 174) dilutes and distorts the uniqueness of the individual cultures. This term results in more policies and strategies that continue the belief that all cultures from the Pacific can be grouped together. This is a dangerous and potentially racist homogenisation of Pacific cultures, as it assumes that the people from all Pacific nations face the same problems and view all issues in the same way, and that it is therefore possible to apply a 'one solution fits all' concept to all peoples from the Pacific.

Recognising cultural diversity needs to be done in a culturally appropriate way. Current Pacific practice strategies within Government departments have a strong attachment to the state-structured term of 'Pacific'. Organisations and institutions within the meso and macro levels need to recognise and work from the basis that it is best to be 'specifically-Pacific' rather than 'pan-Pacific'.

Using a 'specifically-Pacific' base allows each Pacific culture to be recognised fairly. It allows for intervention, meetings and research etc to be carried out using the strengths of individual cultures.

\section{The So'otaga Model}

The model is called 'The So' otaga Model' (see Figure two). I have taken the word 'So' otaga' and its meaning of connection/joining together to label this model and to highlight the importance of connecting the practitioners/workers to the area of social work practice.

The central focal point of this model is the 'Fale' which represents Samoan culture, language and the people. The fale is the essence of where the Samoan culture is born, nurtured, 


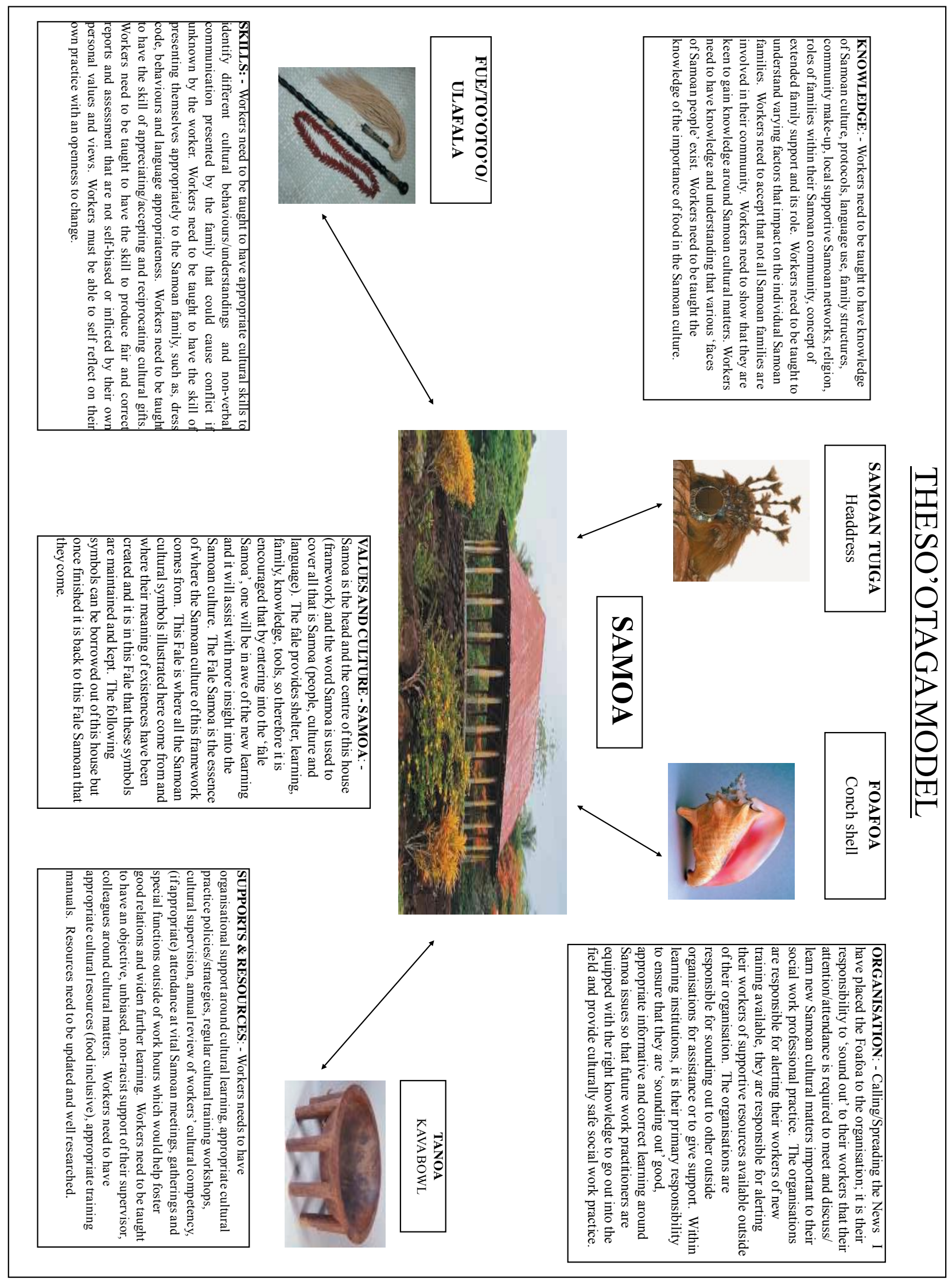


educated, maintained, sheltered, protected and held, The 'Fale' is vital to the survival of the Samoan culture.

The fale is where all the cultural symbols (illustrated in the model) come from and where their meanings have been created. It is in this fale that these symbols are maintained and given life. These cultural symbols used in the model can not connect directly to each, they can only connect going through the fale, as the fale symbolises the heart and life of the Samoan culture.

The cultural symbols illustrated are:

1) Tuiga - (Samoan traditional headdress). This is chosen to symbolise the knowledge that social workers should have. Elements such as: knowledge around culture, protocols, language use, family structures, community make-up, local supportive Samoan networks, religion, the role of families within the local Samoan community, the concept of extended family support, cultural obligations, family roles, survival tasks, gender roles, duties, different make up of Samoan families depending on geographical location and finally social workers need to know the importance of food within the Samoan culture and how to appreciate and reciprocate this protocol.

2) Fue, To'oto'o male Ulafale - (Instruments, tools used by orators and chiefs). These tools are used to support the skills of the orator and can only be used once an orator has been given the duty. To be a well-versed orator is a master skill. This is chosen to symbolise the skills that social workers need. Elements such as: appropriate cultural skills to identify different cultural behaviour, understanding verbal and non-verbal communication, being able to present themselves appropriately in cultural settings, knowing one's place within a cultural gathering, knowing how to relate to different people based on their gender and status, skill of appreciating, accepting and reciprocating cultural gifts and self-reflection on one's own practice.

3) Foafoa - (Conch Shell). This is chosen to symbolise the organisation's responsibility to support their social work staff. In usual village life, the calling of the conch shell alerted the village to danger, immediate attendance, celebratory gatherings, and meetings. Elements such as: alerting their social workers that their attention and attendance is required at new/required training, to bring their attention to other support resources outside their agency, locating supports, to attend meetings to discuss practice issues around working with Samoan families.

4) Tanoa - (Kava Bowl). This is chosen to symbolise resources and supports. In this ceremonial celebration, once everyone gathered has drunk from the kava bowl, they have pledged their commitment to support and provide resources for their particular cause. Elements such as: support from the organisation, cultural learning, appropriate cultural practice policies and strategies, regular cultural training workshops, cultural supervision, an annual review of workers' cultural competency, attendance at vital Samoan meetings which foster interagency networks, the provision of cultural resources such as food when attending important meetings, and finally social workers need to have the organisation's support in ensuring that cultural resources are up-to-date and well resourced. 


\section{Conclusion}

The research question asked, 'What are some appropriate ways of working social work with Samoan people from a Samoan client's perspective?' Practice models and cultural descriptors illustrated by Mulitalo-Lauta (Lalaga Model, 2000), Autagavaia (Concepts important to Fa' asamoa, 2001), Thomsen-Inder (Tanoa Model, 2003) and Kelly and Sewell (Head, Heart and Hand model, 2001) were taken on board and informed an analysis of the stories told by the six participants. From these stories key themes such as inclusiveness, cultural competence, communication (verbal \& non-verbal), empowerment, power dynamics, boundaries and sensitivity unfolded, which in turn brought out the key words/feelings recorded in Table one. The So'otaga Model was born from these findings.

It is my hope that my research has added to other similar research topics, by widening the door of understanding with the hope that a wider door will allow more understanding, learning, intervention and appropriate practice tools to flow through.

At the end of my research I looked back and asked if I have made sure that I covered everything, just like checking that everything in the house is turned off before leaving. I have chosen to leave the 'lights on' to be a beacon of light to other researchers, readers, teachers, students and social workers.

In the Samoan manner I now ask that should any content of this article offend or disrespect anyone, then it be cast upon land not worthy of cultivating.

Fa' afetai tele lava ma ia manuia

Tautala A Faletolu

\section{References}

Autagavaia, M.K. (2001). Social work with Pacific Island communitie. In M. Connolly (Ed.), New Zealand social worker - contexts and practice. Melbourne, Australia: Oxford University Press.

Baba, T. (2004). Pacific and indigenous research: Beyond bondage and patronage. In T. Baba, O. Mahina, N. Williams, \& U. Nabobo-Baba (Eds). Researching the Pacific and indigenous people-Issue and perspectives, pp. 95-104. University of Auckland Press: Centre of Pacific Studies.

Denzin, N. K. \& Lincoln, Y. S. (Eds.) (2000). Handbook of qualitative research (2nd Ed.). Sage Publication.

Earle, D. (1995). Pacific Island Peoples in Aotearoa/New ZEaland: Existing and emerging paradigms. Social Policy, 4, July.

Kelly, A. \& Sewell, S. (2001). With head, heart and hand: Dimensions of community building (4th Ed). Brisbane Australia: Boolarong Press.

Mafile'o, T. (2001). Pasifikan social work theory. Tu Mau Social Work Review, XIII(3).

Mafile'o, T. (2005). Tongan metaphors of social work practice: Hange ha pa kuo Fa'u. Unpublished PhD Thesis, Massey Universty.

Meleisea, M. \& Schoeffel, P. (1998). Samoan families in New Zealand: The cultural content of change. In V. Adair \& R. Dixon (Eds.), The Family in Aotearoa New Zealand. Auckland: Longman.

Mulitalo-Lauta, P. T. M. T. (2000). Fa'asamoa and social work within the New Zealand context. New Zealand: Dunmore Press.

Mutu, T. (2004) Research the Pacific. In T. Baba, O. Mahina, N. Williams, \& U. Nabobo-Baba (Eds), Researching the Pacific and indigenous people - Issue and perspectives, pp. 54-63. University of Auckland Press: Centre of Pacific Studies.

Pilato, T., Su'a, T, \& Crichton-Hill, Y. (1998). A Pacific Islands perspective. Social Work Now, 11, 25-29.

Pulotu-Endermann, K. \& Spoonley, P. (1992). Being Samoan: Samoan ethnicity in New Zealand. In A. D. Trilin \& P. Spoonley (Eds.) New Zealand and international migration. A digest and bibliography: Number 23. Palmerston North: Department of Sociology, Massey University.

Tamasese, K., Peteru, C., \& Waldegrave, C. (1997). O le taeao afua: The new morning: A qualitative investigation into Samoan perspective on mental health and culturally appropriate services. Wellington: The Family Centre.

Southwick, M. (2001). Culture and identity from a Pacific perspective. Tu Mau Social Work Review, XIII(3).

Thomson-Inder (2003). Personal communication. 